\title{
Mesane Kanserinde Radikal Sistektomi Operasyonunun Önemi ve Takip Döneminde Karşılaşılan Komplikasyonlar: Tek Merkez Deneyimi
}

\section{Importance of Radical Cystectomy Operation in Bladder Cancer and Complications Encountered During Follow-up: Single Center Experience}

\author{
Ergün ALMA $^{1}{ }^{(D)}$, Adem ALTUNKOL ${ }^{1}$ (D) , Hakan ERÇiL ${ }^{1}$ (D), Güçlü GÜRLEN ${ }^{1}$ (D), \\ Nevzat Can ŞENER 1 (D) , Zafer Gökhan GÜRBÜZ ${ }^{1}$ (D)
}

1 Sağlık Bilimleri Üniversitesi, Adana Şehir Eğitim ve Araştırma Hastanesi, Üroloji Kliniği, Adana, Türkiye

Öz.

Amaç: Kliniğimizde yapılan radikal sistektomi operasyonlarının onkolojik ve fonksiyonel sonuçlarının değerlendirilmesi.

Materyal ve metod: Eylül 2016 ve Haziran 2019 tarihleri arasında gerçekleştirilen 42 sistektomi hastasının kayıtları retrospektif olarak incelendi. Demografikler, patolojik inceleme sonuçları, diversiyon yöntemleri, hospitalizasyon süreleri, ortalama takip süresi ve oluşan komplikasyonlar değerlendirildi.

Bulgular: Çalışmamız yaş ortalaması $65.1 \pm 8,8$ yıl olan 4 kadın ve 38 erkek hasta olmak üzere toplam 42 hastadan oluşmaktaydı. Ortalama hastanede yatı̧s süreleri $18.7 \pm 8,3$ gün ve ortalama takip süresi $10.8 \pm 6,1$ ay idi. 15 hasta $(\% 35,7)$ sistektomi öncesi neoadjuvan kemoterapi almıştı. Sistektomi materyallerinin patolojik değerlendirmesinde 19 pT1 ve 19 pT2, 6 pT0, 2 pT4 evre saptandı. En sık yapılan diversiyon ileal loop idi. Takip periyodunda 26 (\%61.9) hastada değişik derecelerde komplikasyon izlendi.

Sonuç: Radikal sistektomi operasyonu morbiditesi yüksek ve bazen mortal olabilen bir cerrahi olmasına rağmen onkolojik sonuçları ile beraber değerlendirildiğinde deneyimli merkezlerde başarı ile uygulanabilen bir cerrahi prosedürdür.

Anahtar Kelimeler: Sistektomi; Diversiyon; Illeal loop

Abstract

Background: To evaluate the oncological and functional results of radical cystectomy operations performed in our clinic.

Materials and Methods: The records of 42 cystectomy patients performed between September 2016 and June 2019 were reviewed retrospectively. Demographics, pathological examination results, diversion methods, hospitalization time, mean follow-up and complications were evaluated.

Results: Our study consisted of 42 patients ( 4 female and 38 male) with a mean age of $65.1 \pm 8.8$ years. The mean hospital stay was $18.7 \pm 8.3$ days and the mean follow-up was $10.8 \pm 6.1$ months. Fifteen patients (35.7\%) had received neoadjuvant chemotherapy before cystectomy. Pathologic evaluation of cystectomy materials revealed 19 pT1 and 19 pT2, 6 pT0, 2 pT4 stages. The most common diversion was ileal loop. During the followup period, $26(61.9 \%)$ patients had varying degrees of complication.

Conclusions: Radical cystectomy is a surgical procedure that can be performed successfully in experienced centers when evaluated with its oncologic results, although it is a highly morbid and sometimes mortal surgery.

Key words: Cystectomy; Diversion; lleal loop
Sorumlu Yazar I

Corresponding Author

Dr. Ergün ALMA

Üroloji Kliniği, Sağlık Bilimleri

Üniversitesi, Adana Şehir Eğitim ve

Araştırma Hastanesi, Adana, Türkiye

Tel:05057596371

e-mail: almaerim@yahoo.com

Geliş tarihi / Received:

30.10.2019

Kabul tarihi / Accepted:

13.01.2020

DOI: 10.35440/hutfd.640231 


\section{Giriş}

Mesane kanseri erkeklerde en sık görülen yedinci, her iki cinsiyet değerlendirildiğinde 11. sırada tanı konan kanserdir. Dünyada mesane kanserinin 2012 de yaş standardize mortalite oranı yıllık 100000 erkekte 3,2 ve kadında 0,9 olarak raporlanmıştır. Mesane kanserli hastaların yaklaşık olarak \%75'i kasa invaze değildir(Ta, karsinoma in situ, T1)(1). Radikal sistektomi; metastatik olmayan, detrusör kasına invaze ya da invaze olmayan yüksek dereceli seçilmiş vakalar için altın standarttır. Radikal sistektomi sıklıkla küratif olmasına rağmen, büyük çaplı kohort çalışmalarda \%78 in üzerinde post-operatif komplikasyon geliştiği ve taburcu edildikten 3 ay sonrasına kadar yaklaşık \%15'e kadar bir oranda mortalitesi olduğu raporlanmıştır (2).

Mesane kanseri tedavisinde, onkolojik sonuçları iyileştirerek hastayı kanserden kurtarmak ve bununla birlikte mortalite ve morbiditeyi en aza indirgemek amaçlanmaktadır. Son zamanlarda yüksek vaka volümüne bağlı, cerrahi tekniğin gelişimi, tecrübenin artması, anestezideki gelişmeler ve post-operatif bakımdaki gelişmelerle mortalite ve morbidite de azalma gözlenmiştir(3). Bu çalışmada kiniğimizde son 3 yılda yaptığımız vakaların onkolojik, fonksiyonel sonuçlarını retrospektif olarak değerlendirmeyi amaçladık.

\section{Materyal ve Metod}

Lokal etik komite onayı (Adana Şehir Eğitim ve Araştırma Hastanesi Klinik Araştırmalar Etik Kurulu- 04.12.2019 tarih ve 618 nolu karar) alındıktan sonra Eylül 2016 ve Haziran 2019 tarihleri arasında kliniğimizde mesane tümörü nedeni ile radikal sistektomi operasyonu uyguladığımız 42 hastanın dosyaları ve bilgisayar kayıtları retrospektif olarak incelendi. Hastaların demografik özellikleri, pre-operatif ve post-operatif patolojileri ile radikal sistektomiyi takiben uygulanan üriner diversiyon yöntemleri, hastanede yatış süreleri, vücut kitle indeksleri ve oluşan komplikasyonları değerlendirildi. Hastalar operasyondan bir gün önce hastaneye yatırılarak clear diyet ve mekanik barsak temizliği uygulanmıştı. Hastalara post-operatif birinci gün parenteral beslenme başlandı ve post-operatif 1 ila 3 gün arasında nazogastrik tüp çıkarılarak sıvı gıdalar ile oral beslenmeye geçildi. Bütün hastalarda post-operatif birinci günde mobilizasyon sağlandı. Taburcu sonrası 15-20 günler arasında hastalar kontrole çağrılarak üreter kataterleri geri alındı. Yatı̧ süresi boyunca barsak ya da üreter anostomozu gibi sebepler ile komplikasyon gelişen hastalar ise bu sebeplere yönelik olarak tedavi edildi ve rutin tedavi sürecinin dIşında değerlendirildi.

\section{Operasyon tekniği}

Radikal sistektomi operasyonu erkekte, mesane, prostat ve seminal veziküllerin çevre yağ doku ile beraber çıkartılması ile gerçekleştirildi. Erkeklerde mesane boynu ve prostatik üretrada, kadınlarda trigonda tümör tespit edilen olgularda total üretrektomi de operasyona dahil edildi. Kadında ise mesane, üretra, uterus, serviks ve overler vajen ön duvarı ile beraber çıkartıldı. Tüm hastalara bilateral genişletilmiş pelvik lenfadenektomi yapıldı. Üreteroileal anastomoz için Bricker veya Wallace tekniği uygulandı. Ortotopik mesane yapılması tercih edilen olgularda Studer ileal ortotopik mesane yöntemi tercih edildi.

\section{Bulgular}

Çalışmamız yaş ortalaması $65.1 \pm 8.8$ yıl olan 4 kadın ve 38 erkek hasta olmak üzere toplam 42 hastadan oluşmaktaydı. Hastaların vücut kitle indexi ortalaması $25.0 \pm 1.2$ $\mathrm{kg} / \mathrm{m} 2$ idi. Hastalarımızın ortalama hastanede yatış süreleri $18.7 \pm 8.3$ gün idi ve ortalama takip süremiz ise $10.8 \pm 6.1$ ay idi(Tablo 1).

$\underline{\text { Tablo 1. Demografik özellikler ve patoloji sonuçları }}$

\begin{tabular}{llll}
\hline Değişkenler & Sayı(n:42) & \\
Yaş(yıl) & $65.1 \pm 8.8$ & & \\
VKİ(kg/m2) & $25.0 \pm 1.2$ & & \\
Yatış süresi(gün) & $18.7 \pm 8.3$ & & \\
Takip süresi(ay) & $10.8 \pm 6.1$ & & \\
\hline Patoloji & TUR -M & Re-TUR-M & Sistektomi \\
& (n:6) & (n:42) \\
\hline TaLG & $1(\% 2.5)$ & & \\
TIHG & $19(\% 47.5)$ & $3(\% 7.1)$ & $8(\% 19.0)$ \\
T2HG & $19(\% 47.5)$ & $3(\% 7.1)$ & $18(\% 42.8)$ \\
Kronik enflamasyon & $1(\% 2.5)$ & & \\
pT3a & & & $6(\% 14.2)$ \\
pT4a & & & $2(\% 4.7)$ \\
pT0 & & & $6(\% 14.2)$ \\
Diğer & & $2(\% 4.7)$ \\
LVI & $1(\% 2.5)$ & $6(\% 14.2)$ \\
Squamoz farklılaşma & $2(\% 5.0)$ & & $4(\% 9.5)$ \\
Nöroendokrin tümör & & & $1(\% 2.3)$ \\
CiS & $1(\% 2.5)$ & $1(\% 2.3)$ \\
Lenf nodu pozitifliği & & $3(\% 7.1)$ \\
\hline CiS: Carchoma in situ LVI: & & \\
\hline
\end{tabular}

CiS: Carcinoma in situ LVI: Lenfovasküler invazyon

TUR-M: Transüretral rezeksiyon- Mesane VKI : Vucut kitle indexi

Sistektomi öncesi transüreteral rezeksiyon(TUR-M) sonuçlarına göre ise 19 hastada T1HG, 19 hastada T2HG, 1 hastada kronik enflamasyon ve 1 hastada ise TaLG mesane tümörü patolojisi saptanmıştı. Bu hastalarda unrezektabl olgulara re-TURM yapılmadı ve klinik durum, patoloji sonucu ve tümör yaygınlığına göre sistektomi operasyonu uyguland. Re- TURM yapılan 3 hastada ise T1HG ve 3 hastada ise T2 HG patoloji saptanmıştı. Illk rezeksiyonda saptanan 19 T1HG patolojisi olan hastalardan 5 tanesinde daha önce yapılan BCG tedavinin başarısızlığı mevcut idi. Kalan hastalar tamamı ise rezeke edilemeyecek kadar tümör yükü olan hastalardan oluşmakta idi(Tablo 1). Sistektomi spesimenlerinin incelenmesi sonucunda ise 8 hastada PT1, 18 hastada PT2, 6 hastada PT3a, 2 hastada PT4, 6 hastada PT0, 1 hastada sarkom (jinekolojik orjin) ve 1 hastada ise adenoca (sigmoid kolon orjin) tespit edilmişti. Sistektomi öncesi 13 hastada hidroüreteronefroz mevcut idi ve bu hastalardan sadece 2 tanesinde üreter frozen incelemesinde tümör nedeni ile fazladan rezeksiyon yapılmıştı. Toplam 10 hastada beraberinde varyant histoloji ve 1 has- 
tada ise CIS mevcut idi. 3 hastada lenf nodu pozitifliği saptanmıştı. Sistektomi öncesinde hastalarımızdan 15 tanesi neoadjuvan kemoterapi(NAK) almışlardı.

Hastalarımızda üriner diversiyon yöntemi olarak 34 hastada ileal loop, 6 hastaya üreterokutanostomi ve 2 hastaya ise studer pouch tercih edilmişti. Takip süremiz boyunca toplam 26 hastada (\%61.9) değişik derecelerde komplikasyonlar ile karşılaştık. Bir hastamız post-operatif dönemde pulmoner emboli ve dolaşım yetmezliği nedeni ile ex oldu. Oluşan komplikasyonlarımızın sınıflandırıması modifiye Clavien's- Dindo sınflandırma sistemine göre yapıldı. İzlenen komplikasyonlar beş hastada yara enfeksiyonu , üç hastada ileus, dört hastada kan transfüzyonu gerektiren kanama, bir hastada rektum yaralanması, beş hastada yara eventrasyonu, bir hastada üriner ekstravazasyon ve takiplerde ise üç hastada loop stenozu ile altı hastada üreteroileal anastomoz darlığı idi (Tablo 2).

Tablo 2. Komplikasyonlar ve diversiyon çeşitleri

\begin{tabular}{|c|c|c|}
\hline Değişkenler & Sayı(n:26) & Clavien's-Dindo \\
\hline \multicolumn{3}{|l|}{ Komplikasyonlar } \\
\hline Yara evantrasyonu & $5(\% 19,2)$ & $3 b$ \\
\hline Kanama & $4(15,3)$ & 2 \\
\hline İleus & $3(\% 11,5)$ & 2 \\
\hline Yara enfeksiyonu & $5(\% 19,2)$ & $3 a$ \\
\hline Rektum yaralanması & $1(\% 3,8)$ & 4 \\
\hline Loop stenozu & $3(\% 11,5)$ & $3 b$ \\
\hline Üreteroileal darlık & $6(\% 23)$ & $3 b$ \\
\hline Üriner extravazasyon & $1(\% 3,8)$ & $3 b$ \\
\hline Ölüm & $1(\% 3,8)$ & 5 \\
\hline \multicolumn{3}{|l|}{ Diversiyon } \\
\hline Loop & 34 & \\
\hline Üreterokutanostomi & 6 & \\
\hline Studer & 2 & \\
\hline
\end{tabular}

\section{Tartışma}

Klasik olarak radikal sistektomi operasyonu non- metastatik, kasa invaze (T2-T4a, NO-Nx, M0) hastalıkta uygulanan standart cerrahi işlemdir(4). Radikal sistektomi operasyonu morbiditesi yüksek olduğu kadar mortaliteside yüksek olan bir cerrahidir $(5,6)$. Tanıdan cerrahiye kadar geçen sürenin kısa olmasının rekürrens ve progresyon açısından olumlu sonuçları bulunmaktadır ancak hastaların yaklaşık \%50'si metastatik hastalık nedeni ile kaybedilmektedir(7). Sistektomi ile düşük evreleme olasılığının ortadan kalkması, uygun hastalarda tam olarak kür sağlanabilmesi ve lenfadenektomi ile beraber yapılabilmesi avantajları olarak sayılabilmektedir. Yapılan bazı çalışmalarda ise BCG ile yanıt alınabilecek yaklaşık $\% 50$ oranında bir hasta grubunda ise fazladan yapılmış bir tedavi gibi görünmektedir(8). Bu avantaj ve dezavantajlarına rağmen radikal sistektomi onkolojik sonuçları ile halen hastalar için uygun olan küratif bir cerrahi olarak değerlendirilmektedir(9).

Kas invaziv hastalıkta standart tedavi sistektomi olmakla beraber 1980 lerden beri kullanılan sisplatin bazlı NAK hastalardaki survivali uzatmaktadır(10). NAK ile mikrome- tastatik hastalık yükü azaltılmakta, cerrahi morbidite artmamakta, patolojik olarak pTO, pNO ve negatif cerrahi marjin hedeflenmektedir. NAK ile ilgili majör endişe kaynağı ise sistektominin gecikmesi ve aşırı tedavi olmakla beraber NAK nedeni ile gecikmiş sistektominin survivalde olumsuz etki yarattığına dair herhangi bir yayın da bulunmamaktadır ve EAU klavuzu T2-T4a cNOMO hastalıkta rutin olarak NAK kullanımını kuvvetli olarak önermektedir(1). Yapılan güncel bir çalışmada NAK ile 5 yıllık survivalde net $\% 8$ lik bir düzelmenin sağlandığı bildirilmiştir(11). Geniş bir faz 3 çalışmanın güncellenmesinde ise mortalite riskinin $\% 16$ azaldığı bildirilmiştir(12). Bizim çalışmamızda ise NAK kullanımı oranımız \%35.7 idi ve buna bağlı olarak 6 hastada(\%14.2) patolojik inceleme sonucu PT0 olarak raporlanmıştı. Bu bağlamda biz de her ne kadar küçük bir seri ile yorum yapmak mümkün olmasa da uygun olan tüm hastalarda NAK kullanılmasının gerekli olduğunu düşünmekteyiz.

Radikal sistektomi için günümüze kadar değişik kolon ve ileum diversiyon çeşitleri uygulanmıştır. Çeşitli serilerde kolon ve ileum segmentlerinin seçilmiş hastalarda benzer komplikasyon oranlarına sahip olduğu bildirilmiştir. Yüksek vaka serisi ve uzun takip süresi olan bir çalışmada piyelonefrit (\%5-23), üreteral obstrüksiyon(\%2-22), üriner sistem taşı(\%3-16) ve stoma komplikasyonları (\%5-23) en sık rastlanan komplikasyonlar olarak bildirilmiş ve takip süresi ile komplikasyonların artışının doğru orantılı olduğu vurgulanmıştır(13). Yıllar içerisinde artan cerrahi tecrübe ve merkezlerin yüksek operasyon volümüne rağmen post- operatif ilk 3 ayda halen \%50-64 arasında komplikasyon oranına rastlanımaktadır(14). Bizim çalışmamızda ise postoperatif ilk 3 ayda toplam $\% 61.9$ oranında farklı derecelerde komplikasyon gözlemledik. Bir hastamız pulmoner emboli nedeni ile kaybedilirken, dört hastada trasfüzyon gerektiren kanama oluşmuştu. Bizim hastalarımız da cerrahi sonrasında üriner extravazasyonu devam eden hastalarımızın tamamında öncelikle perkütan nefrostomi ile drenaj yapımıştı. Sadece 2 hastada erken dönemde tekrar opere edilerek üreteroileal anastomoz kaçağı tamir edilmişti. Takip döneminde ise 3 hastamızda loop stenozu ve 5 hastada ise üreteroileal anostomoz darlığı nedeni ile cerrahi müdahale yapılmıştı. Çalışmamız da karşılaştığımız bazı komplikasyonların tedavileri güncel klavuzlara uygun olarak yapılmıştır. Komplikasyon oranlarımız literatür ile uyumludur ve bu sonuçlara göre artan cerrahi deneyim ile komplikasyonları uygun ve zamanında yönetmenin hastalardaki morbidite ve mortaliteyi azaltacağını düşünmekteyiz.

Yaş, radikal sistektomi ve üriner diversiyon tipi ile ilgili tartışmalar hala devam etmektedir. Radikal sistektomi kararı verildiğinde tercih edilecek üriner diversiyonun şekli görülebilecek komplikasyonlar ve hastanın yaşam kalitesi bakımından son derece önemlidir. Mcmullen ve arkadaşları diversiyonun hasta perspektifli olarak seçilmesi gerektiğini 
bildirmişlerdir(15). Ürerosigmoidostomi geçmişte üriner diversiyon için yaygın olarak kullanılan ilk cerrahi teknikti ve anal sfinkter kontinansı kullanılarak etkili bir diversiyon sağlamaktaydı. Bununla birlikte, zaman içinde böbrek fonksiyonunun bozulması, metabolik komplikasyonlar ve sekonder maligniteler için artmış risk, üriner diversiyon olarak faydasını sınırlandırmıştı (13). Bu riskler farklı diversiyon seçeneklerini gündeme taşımıştır. Üriner diversiyon seçimi sadece hasta tercihi ve performans durumu veya komorbiditeye göre değil aynı zamanda cerrahın tecrübesi ve deneyimi gibi birçok faktöre bağlıdır. Ayrıca perioperatif bakım ve hasta eğitimine yardımcı olmak için özel eğitimli personelin mevcudiyeti de önemli bir faktördür (14). Bizim çalışmamızda 34 hastaya ileal loop, iki hastaya studer pouch, komorbiditesi yüksek ve kısa yaşam beklentisi olan altı hastaya ise üreterokutenostomi yöntemi ile üriner diversiyon yapıldı. Kliniğimizde artan cerrahi tecrübe ve perioperatif bakımın standardizasyonu için yapılan klinik içi eğitimler ile komplikasyon oranlarımızın daha da azalmasını ve hasta memnuniyetini artmasını hedeflemekteyiz. Cerrahi yöntemlere bakıldığında son dönemlerde yaygınlaşan ve gittikçe artan öğrenim eğrisi ile robot yardımlı radikal sistektomi gelecek vaat etmektedir. Aslında onkolojik sonuçlarında bir farkl lık olmamakla beraber hastanede kaış süresinin kısa, kan kaybının az olması, önemli avantajları olarak sayılabilmektedir(16,17). Bir çalışmada ise Bochner ve arkadaşları robot yardımlı sistektominin sadece kısa hastanede kalış süresi dışında başka bir avantajını gösterememişlerdir(18). Bansal ve arkadaşları ise robot yardımlı sistektominin ameliyat ve hastanede yatış masrafları dahil açık radikal sistektomiden $\% 18,9$ daha pahalı olduğunu bildirilmiştir(19). Kendi kliniğimizde tüm hastalara açık radikal sistektomi uyguladık. Bu sonucu robotik sistektominin açık cerrahiye göre yüksek maliyetinden ve merkezimizdeki robotun sistektomi operasyonu için yeterince ergonomik olmamasından kaynaklı olduğunu söyleyebiliriz.

Sonuç olarak radikal sistektomi operasyonu morbiditesi yüksek ve bazen mortal olabilen bir cerrahi olmasına rağmen onkolojik sonuçları ile beraber değerlendirildiğinde deneyimli merkezlerde başarı ile uygulanabilen bir cerrahi prosedürdür. Operasyon kararının hasta ile detaylı olarak görüşülerek en doğru tedavi seçeneğinin kararlaştırılmasının en faydalı yöntem olduğu kanatindeyiz.

Çıkar çatışması: Yazarlar çıkar çatışması olmadığını beyan ederler.

Etik Kurul: Bu çalışma Adana Şehir Eğitim ve Araştırma Hastanesi Klinik Araştırmalar Etik kurulunun 04.12.2019 tarih ve 618 sayı numaralı kararı ile onaylanmıştır.

\section{Kaynaklar}

1. J.A. Witjes, M. Bruins, R. Cathomas, E. Compérat, N.C. Cowan, G. Gakis, et al. EAU Oncology Guidelines: Muscle-invasive and Metastatic
Bladder Cancer.https://uroweb.org/ guideline/ Muscle-invasive and Metastatic Bladder Cancer 2019.

2. Michel J, Goel AN, Golla V, Lenis AT, Johnson DC, Chamie K et al. Predicting Short-term Outcomes After Radical Cystectomy Based on Frailty. Urology. 2019;133:25-33.

3. Altan M, Özdemir B, Çıtamak B, Akdoğan B, Özen H. Radikal Sistektomi Cerrahisinin Kalitesi Nasıl Ölçülebilir? Üroonkoloji Bülteni 2014;13:70-74.

4. Hautmann RE, Abol-Enein H, Hafez K, Haro I, Mansson W, Mills RD et al. World Health Organization (WHO) Consensus Conference on Bladder Cancer. Urology. 2007 ;69(1):17-49.

5. Rangarajan K, Somani BK. Trends in quality of life reporting for radical cystectomy and urinary diversion over the last four decades: A systematic review of the literature. Arab J Urol. 2019;17(3):181-194.

6. Audenet F, Sfakianos JP. Evidence of Atypical Recurrences After Robot-Assisted Radical Cystectomy: A Comprehensive Review of the Literature. Bladder Cancer. 2017;3(4):231-6.

7. Lobo N, Mount C, Omar K, Nair R, Thurairaja R, Khan MS. Landmarks in the treatment of muscle-invasive bladder cancer. Nat Rev Urol. 2017;14(9):565-574.

8. Batur AF, Sözen S. Yüksek Riskli Kasa İnvaze Olmayan Mesane Kanserinde Erken Sistektomi mi yoksa Mesane Koruyucu Tedavi mi Tercih edelim? Üroonkoloji Bülteni 2014;13:93-8.

9. Kulkarni GS, Hakenberg OW, Gschwend JE, Thalmann G, Kassouf $W$, Kamat $A$ et al. An updated critical analysis of the treatment strategy for newly diagnosed high-grade T1(previously T1G3) bladder cancer. Eur Urol 2010;57:60-70.

10. Stein JP, Lieskovsky G, Cote R, Groshen S, Feng AC, Boyd S et al. Radical cystectomy in the treatment of invasive bladder cancer: longterm results in 1,054 patients. J Clin Oncol. 2001;19(3):666-75.

11. Yin M, Joshi M, Meijer RP, Glantz M, Holder S, Harvey HA et al. Neoadjuvant Chemotherapy for Muscle-Invasive Bladder Cancer: A Systematic Review and Two-Step Meta-Analysis. Oncologist. 2016;21(6):708-15.

12. Griffiths G, Hall R, Sylvester R, Raghavan D, Parmar MK. International phase III trial assessing neoadjuvant cisplatin, methotrexate and vinblastine chemotherapy for muscle-invasive bladder cancer: longterm results of the BA06 30894 trial. J Clin Oncol. 2011;29(16):2171-7. 13. Lee RK, Abol-Enein H, Artibani W, Bochner B, Dalbagni G, Daneshmand $S$ et al. Urinary diversion after radical cystectomy for bladder cancer: options, patient selection, and outcomes. BJU Int. 2014;113(1):1123.

14. Kiss B, Burkhard FC, Thalmann GN. Open radical cystectomy: still the gold standard for muscle invasive bladder cancer. World J Urol. 2016;34(1):33-9.

15. McMullen CK, Kwan ML, Colwell JC, Munneke JR, Davis JV, Firemark A et al. Recovering from Cystectomy: Patient Perspectives. Bladder Cancer. 2019;5(1):51-61.

16. Son SK, Lee NR, Kang SH, Lee SH. Safety and Effectiveness of Robot-Assisted Versus Open Radical Cystectomy for Bladder Cancer: A Systematic Review and Meta-Analysis. J Laparoendosc Adv Surg Tech A. 2017;27(11):1109-20.

17. Davis RB, Farber NJ, Tabakin AL, Kim IY, Elsamra SE. Open versus robotic cystectomy: Comparison of outcomes. Investig Clin Urol. 2016;57 (1):36-43.

18. Bochner BH, Dalbagni G, Sjoberg DD, Silberstein J, Keren Paz GE, Donat SM et al. Comparing Open Radical Cystectomy and Robot assisted Laparoscopic Radical Cystectomy: A Randomized Clinical Trial. Eur Urol. 2015;67(6):1042-50.

19. Bansal SS, Dogra T, Smith PW, Amran M, Auluck I, Bhambra M et al. Cost analysis of open radical cystectomy versus robot-assisted radical cystectomy. BJU Int. 2018;121(3):437-44. 